\title{
Factors That Affect Mortality Rates in Elderly Hip Fracture Patients
}

\author{
*Serdar Yuksel M.D, M. Akif Gulec M.D \\ Bagcılar Training and Research Hospital, Orthopaedic and Traumatology Department, \\ Istanbul/Turkey \\ *serdar84yuksel@gmail.com
}

\begin{abstract}
:
Introduction: Hip fractures are primarily seen in elderly patients. Older age and accompanying diseases leads to negative outcomes in this patient group. More than 320,000 cases of hip fractures are diagnosed every year in the U.S.A and there is a mortality rate of 14-36\% in the first year after surgery. The aim of our research was to study factors that affect mortality.
\end{abstract}

Methods: For this purpose, 115 patients over the age of 65 who received hip fracture operations in our clinic were evaluated. Patients with hip fractures due to traffic accidents or from falling down from heights and pathological fractures were excluded.

Results: It was observed that the age at the time of fracture, 2 or more days of suspended time before the operation, high values of ASA score, an intensive care unit stay, used anaesthesia type and presence of accompanying diseases in the single-variable model were significant risk factors for patients in terms of mortality $(p<0.05)$. The age at the time of fracture and 2 or more days of suspending time before operation were found to be significant independent variables in terms of mortality $(p<0.05)$

Conclusion: We assume that multi-disciplinary geriatric care will positively affect post-fracture results and probably reduce treatment costs. According to data collected from our study, the age of patients and two or more suspended days before the operation were significant independent risk factors in terms of mortality.

Keywords: Hip fracture, mortality, geriatrics

\section{INTRODUCTION}

As life expectancy increases, the elderly population also increases. In parallel with this, the number of elderly patients who undergo surgery for hip fractures is on the rise ${ }^{1}$. Elderly hip fractures continue to be a highly critical problem in the world in terms of both families and healthcare systems ${ }^{1}$. Its prevalence and accompanying morbidity are on the rise ${ }^{2}$. Every year, 320,000 new hip fracture cases are diagnosed in the U.S.A. It is expected that the number will rise to 580,000 in 2040 and related cost will be 10 billion dollars ${ }^{1}$. It is assumed that 6 million elderly hip fracture cases will be seen in the world by $2050^{3}$. Hip fracture causes reductions in functionality and quality of life ${ }^{4}$. Furthermore, these fractures have a mortality rate of 7-14\% during the hospital stay period and $14-36 \%$ in the first year after the operation ${ }^{2,4,5}$. Additionally, hip fractures are complicated enough to require revision surgery at the rate of $0-49 \%$ and this fact is related to the kind of fracture and the type of used surgical procedure ${ }^{4}$.

More effort has been made to enhance the results of elderly hip fracture patients in recent years ${ }^{6}$. For instance, in the 20 years between 1980 and 2000, the number of deaths caused by coronary artery diseases decreased by $40 \%$ in the U.S.A, which translates to the prevention of 340,000 deaths a year. It has been announced that nearly half of this rate was ensured through the use of evidence-based medical treatment ${ }^{7}$. Despite the improvements in implant technology, surgical techniques, nursing care, anaesthetics and rehabilitation programs, hip fractures still have high rates of morbidity and mortality in elderly populations ${ }^{8,9}$. Lots of surveys study the factors that are considered to affect mortality following hip fractures. These factors include age, gender, the kind of fracture, the American Society of Anaesthesiologists (ASA) score, surgery time, surgery type and anaesthesia. However, there are limited numbers of studies where all these aforementioned factors were reliably analysed. 
We have retrospectively analysed 115 cases with intertrochanteric femur fractures and collum femoris fractures in our clinic between 2013-2014 with the aim of determining the relationship between the aforementioned factors and mortality rates in the first year after surgery.

\section{Materials AND MethodS}

Out of 195 patients over the age of 65 who were operated on 2013-2014, 115 patients with intertrochanteric femur fractures and collum femoris fractures who underwent ambulatory care before surgery and whose clinical and demographic information were available were included in the research. Patients with hip fractures due to traffic accidents or from falling down from heights and pathological fractures were excluded. Fracture types were routinely evaluated and divided into two groups as intertrochanteric femur and collum femoris fractures for the purpose of treating the two types of fractures with different surgical methods. Patient charts were evaluated for detailed analyses of ASA scores, suspending times before surgery, total stays in service, if existing - stays in intensive care, total operation times, accompanying comorbid diseases, ages and fracture types of the patients. As information about the severity of comorbid diseases were not available in patient charts, patients were divided into two groups as those with comorbid diseases and those without comorbid diseases, notwithstanding the number of comorbid diseases. Patients were recalled to see whether they are alive or not in the first year after surgery. In the case of mortality, patients' relatives were asked about death times in order to determine the relationship between the aforementioned factors and mortality.

\section{Statistical Analysis}

Standard deviation, median minimum/maximum frequencies and proportional values were used as the definitive data statistics. Distributions of the variables were calculated using the KolmogorovSmirnov test. In the quantitative data analysis, the Mann-Whitney U test was used. When conditions were not suitable for chi-square testing in the analysis of qualitative data, the Fischer exact test was used. Effect levels were rated through single-variable and multi-variable logistical regression analyses. All analyses were made with SPSS 22.0 software. Results were evaluated with a significance of $\mathrm{p}<0.05$ level and confidence interval of $95 \%$.

\section{RESUltS}

Table1. Demographic characteristics of the patients

\begin{tabular}{|c|c|c|c|c|c|}
\hline & & Min-Max & Median & \multicolumn{2}{|c|}{ Ave. \pm 5. d. $/ \mathrm{n}-\%$} \\
\hline \multicolumn{2}{|l|}{ Age at the time of fracture } & $61,0-97,0$ & 79,0 & \multicolumn{2}{|c|}{$77,5 \pm 8,1$} \\
\hline \multirow{2}{*}{ Gender } & Female & & & 70 & $60,9 \%$ \\
\hline & Male & & & 45 & $39,1 \%$ \\
\hline \multirow{3}{*}{ ASA } & $|-| \mid$ & & & 12 & $10,4 \%$ \\
\hline & III & & & 40 & $34,8 \%$ \\
\hline & IV & & & 63 & $54,8 \%$ \\
\hline \multirow[t]{3}{*}{ surgery timing (day) } & & $0,0-8,0$ & 2,0 & \multicolumn{2}{|c|}{$2,6 \pm 1,3$} \\
\hline & \multicolumn{2}{|l|}{$\leq 2$ days } & & 58 & $50,4 \%$ \\
\hline & $2>$ days & & & 57 & $49,6 \%$ \\
\hline \multicolumn{2}{|l|}{ Lenght of stay } & $2,0-41,0$ & 6,0 & \multicolumn{2}{|c|}{$6,8 \pm 4,3$} \\
\hline \multicolumn{2}{|l|}{ Operation time (min) } & $25,0-135,0$ & 60,0 & \multicolumn{2}{|c|}{$64,5 \pm 28,6$} \\
\hline \multirow{2}{*}{ ICU stay } & No & & & 96 & $83,5 \%$ \\
\hline & Yes & & & 19 & $16,5 \%$ \\
\hline \multirow{2}{*}{ Side of fracture } & Right & & & 61 & $53,0 \%$ \\
\hline & Left & & & 54 & $47,0 \%$ \\
\hline \multirow{2}{*}{ Type of anesthesia } & Regional Bloc & & & 52 & $45,2 \%$ \\
\hline & Spinal & & & 63 & $54,8 \%$ \\
\hline \multirow{2}{*}{ Accompanying disease } & No & & & 20 & $17,4 \%$ \\
\hline & Yes & & & 95 & $82,6 \%$ \\
\hline \multirow{2}{*}{ Type of fracture } & ITF & & & 58 & $50,4 \%$ \\
\hline & Collum & & & 57 & $49,6 \%$ \\
\hline
\end{tabular}

Age and gender distributions, ASA scores, suspended times before the operation, total stay time in hospital, intensive care stays, fracture distributions, used anaesthesia types and fracture types of patients are summarised in the table below (Table 1). There were 70 female and 45 male patients in the study. 12 patients had a score of ASA I-II while 40 had ASA III and 63 had ASA IV. 50.4\% of the 
patients were operated in 2 days while $49.6 \%$ were operated after 2 days. The average hospital stay was 6.8 days. The average operation time was 64.5 mins. $83.5 \%$ of the patients did not stay in intensive care. $53 \%$ of the patients had fractures on the right side of their body while $47 \%$ had fractures on the left. 54.8\% of the patients underwent regional anaesthesia while $45.2 \%$ received spinal anaesthesia. $82.6 \%$ of the patients had one or more comorbid diseases. $50.5 \%$ of the patients had intertrochanteric femur fractures while $49.5 \%$ had collum femoris fractures( Table-1). 33 patients died in the first year, which gives a mortality rate of $28.6 \%$ in the first year. The age of the patients at the time of fracture, ASA distributions, suspended times, rate of stay in intensive care unit, rate of spinal anaesthesia and rate of accompanying diseases were significantly higher than those who survived $(\mathrm{p}<0.05)$. Gender distribution, time until surgery, operation times, fracture-side distributions and fracture types did not show significant differences between patients who died and survived $(\mathrm{p}>0.05)$ (Table 2).

Table2. Distribution of variables in non- and surviving patients

\begin{tabular}{|c|c|c|c|c|c|c|c|c|c|c|}
\hline & & \multicolumn{4}{|c|}{ Live } & \multicolumn{4}{|c|}{ Dead } & \multirow{2}{*}{$\mathrm{p}$} \\
\hline & & \multicolumn{2}{|c|}{ Ave. \pm 5. d. $/ n-\%$} & \multicolumn{2}{|c|}{ Med(Min-Max) } & \multicolumn{2}{|c|}{ Ave. \pm s.d. $/ n-\%$} & \multicolumn{2}{|c|}{ Med(Min-Max) } & \\
\hline \multicolumn{2}{|c|}{ Age at the time of fracture } & 74,9 & $\pm 7,6$ & 73,0 & $61,0-93,0$ & 84,1 & $\pm 4,7$ & 83,0 & $74,0-97,0$ & 0,000 \\
\hline \multirow{2}{*}{ Gender } & Female & 46 & $56 \%$ & & & 24 & $73 \%$ & & & \multirow{2}{*}{0,098} \\
\hline & Male & 36 & $44 \%$ & & & 9 & $27 \%$ & & & \\
\hline \multirow{3}{*}{ ASA } & $|-| \mid$ & 12 & $15 \%$ & & & 0 & $0 \%$ & & & \multirow{3}{*}{0,002} \\
\hline & III & 33 & $40 \%$ & & & 7 & $21 \%$ & & & \\
\hline & IV & 37 & $45 \%$ & & & 26 & $79 \%$ & & & \\
\hline \multicolumn{2}{|c|}{ surgery timing (day) } & \multicolumn{2}{|c|}{$2,4 \pm 1,3$} & 2,0 & $0,0-8,0$ & \multicolumn{2}{|c|}{$3,2 \pm 1,1$} & 3,0 & $1,0-6,0$ & 0,000 \\
\hline \multirow{2}{*}{$\begin{array}{l}\text { surgery } \\
\text { timing }\end{array}$} & $\leq 2$ days & 51 & $62 \%$ & & & 7 & $21 \%$ & & & \multirow{2}{*}{0,000} \\
\hline & 2> days & 31 & $38 \%$ & & & 26 & $79 \%$ & & & \\
\hline \multicolumn{2}{|l|}{ Lenght of stay } & \multicolumn{2}{|c|}{$6,9 \pm 5,0$} & 6,0 & $2,0-41,0$ & \multicolumn{2}{|c|}{$6,3 \pm 2,0$} & 6,0 & $2,0-11,0$ & 0,905 \\
\hline \multicolumn{2}{|c|}{ Operation time (min) } & 62,0 & $\pm 27,6$ & 55,0 & $25,0-130,0$ & 70,6 & $\pm 30,5$ & 65,0 & $25,0-135,0$ & 0,136 \\
\hline \multirow{2}{*}{ ICU* stay } & No & 74 & $90 \%$ & & & 22 & $67 \%$ & & & \multirow{2}{*}{0,002} \\
\hline & Yes & 8 & $10 \%$ & & & 11 & $33 \%$ & & & \\
\hline \multirow{2}{*}{ Fracture side } & Right & 45 & $55 \%$ & & & 16 & $48 \%$ & & & \multirow{2}{*}{0,534} \\
\hline & Left & 37 & $45 \%$ & & & 17 & $52 \%$ & & & \\
\hline \multirow{2}{*}{$\begin{array}{l}\text { Type of } \\
\text { anesthesia }\end{array}$} & Regional Bloc & 30 & $37 \%$ & & & 22 & $67 \%$ & & & \multirow{2}{*}{0,003} \\
\hline & Spinal & 52 & $63 \%$ & & & 11 & $33 \%$ & & & \\
\hline \multirow{2}{*}{$\begin{array}{l}\text { Accompanying } \\
\text { disease }\end{array}$} & No & 20 & $24 \%$ & & & 0 & $0 \%$ & & & \multirow{2}{*}{0,002} \\
\hline & Yes & 62 & $76 \%$ & & & 33 & $100 \%$ & & & \\
\hline \multirow{2}{*}{$\begin{array}{l}\text { Type of } \\
\text { fracture }\end{array}$} & ITF & 43 & $52 \%$ & & & 15 & $45 \%$ & & & \multirow{2}{*}{0,498} \\
\hline & Kollum & 39 & $48 \%$ & & & 18 & $55 \%$ & & & \\
\hline
\end{tabular}

It was observed that the age at the time of fracture, 2 or more days of suspended time before the operation, high values of ASA score, intensive care unit stay, anaesthesia type and presence of accompanying diseases in the single-variable model were significant risk factors for patients in terms of mortality $(\mathrm{p}<0.05)$. The age at the time of fracture and 2 or more days of suspended time before operation were found to be significant independent variables in terms of mortality $(p<0.05)$ (Table $3)$.

Table3. Factors that affect mortality

\begin{tabular}{|c|c|c|c|c|c|c|}
\hline & \multirow{2}{*}{\multicolumn{3}{|c|}{ Single-Variable Model }} & \multirow{2}{*}{\multicolumn{3}{|c|}{ Multi-Variable Model }} \\
\hline & & & & & & \\
\hline & OR & $\mathrm{Cl} 95 \%$ & $\mathrm{p}$ & OR & $\mathrm{Cl} 95 \%$ & $\mathrm{p}$ \\
\hline Age at the time of fracture & 1,22 & $1,12-1,32$ & 0,000 & 1,23 & $1,11-1,36$ & 0,000 \\
\hline surgery timing $2>$ Days & 6,11 & $2,37-15,74$ & 0,000 & 8,79 & $2,66-29,07$ & 0,000 \\
\hline ASA & 4,11 & $1,75-9,65$ & 0,001 & & & \\
\hline ICU* stay & 4,62 & $1,66-12,92$ & 0,003 & & & \\
\hline Type of anesthesia & 0,29 & $0,12-0,68$ & 0,004 & 0,32 & $0,11-0,96$ & 0,042 \\
\hline Accompanying disease & $>100$ & $>100->100$ & 0,000 & & & \\
\hline
\end{tabular}

Logistics Regresyon

- Intensive care unit 


\section{DISCUSSION}

With the increase in general life expectancy, the frequency of hip fractures in the elderly population also increases, leading to growing medical and social problems. The incidence of hip fracture in a lifetime is $5 \%$ in men and $18 \%$ in women ${ }^{5}$. Statistically, no significant decrease has been observed in mortality in the first year after surgery. There is a limited number of studies which investigated mortality rates in these patient group and the results are not consistent with each other. Brauer et al. (2009) conducted a retrospective research with 786,717 patients, where they stated that mortality rates in both women and men had shown significant decreases in the last 20 years ${ }^{11}$. They showed that mortality rates had decreased from $41 \%$ to $33 \%$ in men and from $24 \%$ to $22 \%$ in women. On the other hand, Haleem et al. (2008) conducted a systematic collective study out of 36 articles published between 1959 and 1998 and discovered that mortality rates had shown no significant decrease in the last four decades ${ }^{10}$. They stated that mortality rates decreased from $27 \%$ to $22 \%$ from the 1960 s to the $1990 \mathrm{~s}^{10}$. We have not come up with a statistically significant difference between mortality rates and gender. Literature shows that mortality rates in men are higher ${ }^{11}$. We relate the result we found to: a higher average age, which we considered an independent risk factor, and accompanying diseases among women patients in the group of 115 patients. Older age was the primary factor that affected post-fracture mortality ${ }^{8} .1$ year mortality rate of $28.6 \%$ in our study is similar with the literature. Literature shows a mortality rate of $14-36 \%$ in these patient population. We observed that: older age at the time of fracture, 2 or more suspended days before surgery, higher ASA scores, longer intensive care unit stays and additional diseases were significant risk factors in terms of mortality ( $>0.05$ ). However, we noticed that only the age at the time of fracture and 2 or more suspended days before surgery were independent risk factors for mortality. Bottle and Aylin (2006) found that higher age and distorted cognitive functions before hip fractures increased mortality rates after the hip fracture ${ }^{12}$. There are various opinions about the effect of suspended time before surgery on mortality. As very old patients generally have at least one comorbid disease, their evaluation before surgery might take time. Zuckerman et al. (1996) showed in their study that more than 3 suspended days for fracture fixation doubles the mortality rate ${ }^{13}$.

There are studies that show more positive results are obtained and mortality rates in 1 year decreased as hospital stay time decreases and fractures are fixed within 24 hours.

On the other hand, there are studies that show suspended time until surgery does not negatively affect mortality ${ }^{15,16}$. Moran et al. (2005) showed that suspending time until surgery to four days does not affect post-operative mortality ${ }^{17}$. Verbeek et al. (2008) stated that longer suspended times before surgery is associated with infections, post-operative complications and longer hospital stay ${ }^{18}$. We found that mortality rates in the group that waited more than 2 days before surgery were significantly higher than the group that did not. That is why we consider surgery should be performed within the shortest time. Although there are publications that allege that earlier surgery does not affect mortality, there is a consensus on the fact that it reduces the prevalence of pressure sores, enables earlier mobilization, helps returning to pre-operational activity levels and reduces infection in urinary and respiratory systems ${ }^{18}$.

Operation is advised for the treatment of elderly hip fractures. Many publications have shown that conservative treatment increases mortality and morbidity in elderly patients ${ }^{19}$. Lower mortality rates are recorded for patients treated with internal fixation and ostheosynthesis compared to those treated with hemiarthroplasty ${ }^{20}$. However, we could not detect any statistically significant differences between the group with intertrochanteric femur fractures (IFF) that received ostheosynthesis and the group with collum femoris fractures that received hemiarthroplasty in terms of mortality. The operation time in the IFF group was found to be significantly shorter. However, we did observe the expected positive affect on mortality. Kopp et al. (2009) showed that fracture type is not related with mortality rates ${ }^{21}$. Avakian et al. (2012) conducted a study where they compared patient groups that were treated with DHS (dynamic hip screw) and PFN (proximal femoral nail). They could not find a statistically significant difference between the two groups in terms of operation times, hospital stay times, first mobilization times and complication rates ${ }^{22}$.

O'Hara et al. (2000) could not find any statistically significant differences between general and regional anaesthesia in terms of mortality, suggesting anaesthesia to be regarded independent from mortality. They stressed that, independently from anaesthesia itself, factors like older age, cardiovascular diseases, pulmonary diseases, diabetes and having weak physical conditions increased 
mortality rates during anaesthesia ${ }^{23}$. We found in our study that regional anaesthesia significantly reduced mortality rate compared to spinal anaesthesia. Thus, we assume regional anaesthesia is a more appropriate option for this group of patients. We suggest that elderly patients with cardiac problems who cannot tolerate spinal anaesthesia due to existing cardiac problems are adversely affected by spinal anaesthesia. Patients with ASA III and IV show increased mortality rates after hip fracture surgery $^{24}$. We found that higher ASA scores lead to significantly higher mortality rates.

There are some limitations in our study. We could not analyse complications related to fractures and comorbid diseases, and their specific effects on mortality. Whether the disease is compensated, and whether an early or advanced stage disease will affect the clinical course. Based on retrospective file analysis, we assumed additional diseases as present or non-present since we could not determine information about the stages and clinical courses of additional diseases. As our study was a retrospective one and had a limited sample size, the results from our study should be evaluated meticulously. We think that further prospective and multi-centred studies are needed in this area.

According to the data we collected in our study, the age, the time of fracture and 2 or more suspended days before surgery were observed as independent risk factors in terms of mortality $(p<0.05)$. Elderly patients with hip fractures should be carefully evaluated with a multi-disciplinary approach that encompasses many clinics from the time when patients are hospitalized and then until discharge and they should be operated and mobilized within the shortest possible time. We assume that this is the only way that better clinical results can be yielded and mortality rates can be reduced. We think that this kind of approach will reduce healthcare expenses and social problems for elderly patients and families who undertake their care.

\section{REFERENCES}

[1] Cooper C, Campion G, Melton L J. Hip fractures in the elderly: a world-wide projection. Osteoporos Int 1992; 2(6): 285-9.

[2] Schemitsch E, Bhandari M. Femoral neck fractures: controversies and evidence. J Orthop Trauma 2009; 23 (6): 385.

[3] Cummings S R, Rubin S M, Black D. The future of hip fractures in the United States. Numbers, costs and potential effects of post menopausal estrogen. Clin Orthop 1990; (252): 163-6.

[4] Murphy D K, Randell T, Brennan K L, et al. Treatment and displacement affect the reoperation rate for femoral neck fracture. Clin Orthop 2013; (471) (8): 2691-702

[5] Weller I, Wai E K, Jaglal S, Kreder H J. The effect of hospital type and surgical delay on mortality after surgery for hip fracture. J Bone Joint Surg (Br) 2005; 87: 361-6.

[6] Setoguchi S, Glynn R J, Avorn J, et al. Improvements in long-term mortality after myocardial infarction and increased use of cardiovascular drugs after discharge: a 10-year trend analysis. $\mathrm{J}$ Am Coll Cardiol 2008; 51 (13): 1247-54.

[7] Ford E S, Ajani U A, Croft J B, et al. Explaining the decrease in U.S. deaths from coronary disease, 1980-2000. N Engl J Med 2007; 356 (23): 2388-98.

[8] Jamal Sepah Y, Umer M, Khan A et al (2010) Functional outcome, mortality and in-hospital complications of operative treatment in elderly patients with hip fractures in the developing world. Int Orthop 34(3):431-435.

[9] Smektala R, Endres HG, Dasch B (2008) The effect of time to surgery on outcome in elderly patients with proximal femoral fractures. BMC Musculoskelet Disord 9:171.

[10] Haleem S, Lutchman L, Mayahi R, et al. Moratlity following hip fracture: trends in geographical variations over the last 40 years. Injury 2008; 39 (10): 1157-63.

[11] Brauer C A, Coca-Perraillon M, Cutler D M, Rosen A B. Incidence and mortality of hip fractures in the United States. JAMA 2009; 302 (14): 1573-9.

[12] Bottle A, Aylin P. Mortality associated with delay in operation after hip fracture: observational study. BMJ 2006; 332 (7547): 947-51.

[13] Zuckerman JD (1996) Hip fracture. N Eng J Med 334:1519-1525

[14] Orosz GM, Magaziner J, Hannan EL (2004) Association of timing of surgery for hip fracture and patient outcomes. JAMA 29:1738-1743

[15] Carretta E, Bochicchio V, Rucci P et al (2011) Hip fracture:effectiveness of early surgery to prevent 30-day mortality. Int Orthop 35(3):419-424 
[16] Lefaivre KA, Macadam SA, Davidson DJ et al (2009) Length ofstay, mortality, morbidity and delay to surgery in hip fractures. J Bone Joint Surg [Br] 91(7):922-927

[17] Moran CG, Wenn RT, Sikand M et al (2005) Early mortality afterhip fracture: is delay before surgery important? J Bone Joint Surg [Am] 87(3):483-489

[18] Verbeek DO, Ponsen KJ, Goslings JC et al (2008) Effect of surgical delay on outcome in hip fracture patients: a retrospective multivariate analysis of 192 patients. Int Orthop 32(1):13-18

[19] Jain R, Basinski A, Kreder HJ (2003) Nonoperative treatment of hip fractures. Int Orthop 27(1):11-17

[20] Bhandari M, Devereaux PJ, Swiontkowski MF et al (2003) Internal fixation compared with arthroplasty for displaced fractures of the femoral neck A meta-analysis. J Bone Joint Surg [Am] 85-A(9):1673-1681

[21] Kopp L, Edelmann K, Obruba P et al (2009) Mortality risk factors in the elderly with proximal femoral fracture treated surgically. Acta Chir Orthop Traumatol Cech 76(1):41-46

[22] Avakian Z, Shiraev T, Lam L, Hope N (2012) Dynamic hip screws versus proximal femoral nails for intertrochanteric fractures-. ANZ J Surg 82(1-2):56-59

[23] O'Hara DA, Duff A, Berlin JA et al (2000) The effect of anesthetic technique on postoperative outcomes in hip fracture repair-. Anesthesiology 92(4):947-957

[24] Paksima N, Koval KJ, Aharonoff GB et al (2008) Predictors of mortality after hip fracture: a 10 year prospective study. Bull NYU Hosp Joint Dis 66(2):111-117 